ISSN1027-5495. Functional Materials, 23, No.2 (2016), p. 293-299

doi:http://dx.doi.org/10.15407/fm23.02.293

(C) 2016 - STC “Institute for Single Crystals"

\title{
Computer simulation of the compressive failure of porous material through Distinct Lattice Spring Model
}

\author{
You Shuang*,, Zhao Gaofeng ${ }^{2}$, Ji Hongguang' \\ ${ }^{1}$ School of Civil and Environment Engineering, \\ University of Science \& Technology Beijing, Beijing 100083, China \\ ${ }^{2}$ Rock Mechanics Laboratory (LMR), Ecole Polytechnique Federale \\ de Lausanne (EPFL), Lausanne, Switzerland
}

Received December 7, 2015

This paper presents the computer simulation of dynamic failure process of porous material through a discrete numerical method. The motivation of this study is to investigate the influence of porous on the compressive failure of material by using the Distinct Lattice Spring Model (DLSM). Firstly, the basic theory of the DLSM is introduced. Due to its inherit discrete nature, DLSM is more suitable to simulate the fracturing process problems than conventional continuum based methods. Then, the methodology used to represent the porous materials is presented. Following this, details of DLSM modeling on the failure process of the porous material under dynamic loading are provided. Finally, the influence of loading ratio and porous on the final strength of the material are presented and analyzed. It indicates that porous play a significant influence on the dynamic compressive strength of material.

Keywords: DLSM, porous material, dynamic failure, SHPB

Работа представляет компьютерное моделирование динамики процесса разрушения пористого материала с помощью дискретного численного метода. Мотивация данного изучения - исследовать влияния пор на разрушение сжатием материала с использованием модели определённой решётки пружин (DLSM). Прежде всего, вводится базовая теория DLSM. Благодаря унаследованной им дискретной природе, DLSM более пригоден для моделирования задачи процесса разрушения, чем традиционные континуальные методы. Далее изложена методология, использованная для представления пористого материала. Представлены детали DLSM-моделирования процесса разрушения пористого материала под динамической нагрузкой. представлено и проанализировано влияние относительного нагружения и пор на результирующую прочность материала. Показано, что поры имеют значительное влияние на прочность материала при динамическом сжатии.

Комп'ютерне моделювання руйнування стисненням пористого матеріалу за допомогою моделі певних грат пружин. Ю Чуанг, Жао Гаобенг, Йі Хонггуанг

Робота представляе комп'ютерне моделювання динаміки процесу руйнування пористого матеріалу за допомогою дискретного чисельного методу. Мотивація даного вивчення досліджувати впливи пір на руйнування стисненням матеріалу з використанням моделі певних грат пружин (DLSM). Перш за все, вводиться базова теорія DLSM. Завдяки успадкованій їм дискретній природі, DLSM придатніший для моделювання завдання процесу руйнування, чим традищійні континуальныеметоди. Далі викладена методологія використана для представлення пористого матеріалу. Представлені деталі DLSM-моделювання процесу руйнування пористого матеріалу під динамічним навантаженням. представлено і проаналізовано вплив відносного вантаження і пір на результуючу міџність матеріалу. Показано, що пори мають значний вплив на міцність матеріалу при динамічному стисненні. 


\section{Introduction}

In sedimentary clay formations, rock anisotropy plays an important role in the stability of underground excavations and surface excavations. It is also a critical factor in controlling borehole deviation, stability, deformation and failure. It is known that the anisotropic behavior of rock/soil material is determined by the joints, the micro foliation planes or the bedding planes. For this reason, the continuum based numerical method, e.g., FEM, is not suitable to model the anisotropic failure process of such kind of materials. Moreover, most materials are actually heterogeneous when viewed at microscopic level. For example, rock materials at microscope are better to be treated as an assemblage of particles bonded together rather than a homogenous material. Recently, researchers realized that it is of great importance to consider the orientation of weakness layer when studying the mechanical properties of anisotropic materials [1,2]. The Distinct Lattice Spring Model (DLSM) [3,4] is selected in this paper to simulate the failure process of such anisotropic material as a host medium for nuclear waste disposal galleries. The DLSM is a discrete numerical model which based on the RMIB theory [5,6]. In DLSM, the material is treated as a group of discrete particles linked by springs. The failure process is represented by fracturing of these springs. The DLSM model has been successfully used in the study of dynamic strength of brittle rock materials [3] and dynamic cracking propagation of PMMA [7]. Recently, the parallel version of DLSM is also developed [8]. Verifications and examples of DLSM on modeling elastic, elastic dynamic and dynamic fracturing problems can be found in $[4,7]$.

The paper is organized as follows. Firstly, the basic principle and formulas used in DLSM is introduced. Then, the used methodology to model anisotropic material in DLSM is introduced. Following this, the development of excavation damage zone of nuclear waste disposal galleries in anisotropic medium under mechanical unloading is simulated. Finally, some conclusions are derived.

\section{The Distinct Lattice Spring Model}

The Distinct Lattice Spring Model (DLSM) is a microstructure based numerical model based on the RMIB theory [5,6] which is an extension of VMIB model [9]. In DLSM, material is discretized into mass particles linked through distributed bonds (see Fig1(a)). Whenever two particles are detected in contact, they are linked together through bonds between their center points. The multi-dimensional internal bond is adopted, and it include one normal bond and one shear bond. By adding the shear spring, the proposed model can represent the diversity of the Poisson's ratio. The local strain of the spring is calculated through a least square method which makes the model possessing meshless properties. Due to the explicit considerations of the microstructure of the material, the proposed model can give more realistic modeling of material failure behavior than continuum based methods. Based on Cauchy-born rules and the hyperelastic theory, the relationship between the micromechanical parameters and the macro material constants, i.e. the Young's modulus and the Poisson ratio is obtained as follows:

$$
k_{n}=\frac{3 E}{\alpha^{3 D}(1-2 v)}, k_{s}=\frac{3(1-4 v) E}{\alpha^{3 D}(1+v)(1-2 v)}
$$

where $k_{n}$ is the normal stiffness of the spring, $k_{\mathrm{s}}$ shear stiffness, $E$ Young's modulus, $v$ Poisson ratio and $\alpha^{3 D}$ is a microstructure geometry coefficient which can be obtained from:

$$
\alpha^{3 D}=\frac{\sum l_{i}^{2}}{V}
$$

where $l_{i}$ is the original length of the $i$ th bond, $V$ is the volume of the geometry model. The details of this model can be found in [3].

DLSM is a particle based numerical method. The particles and springs make a whole system which represents the material. For this system, its motion equation is expressed as

$$
[\mathbf{K}] \mathbf{u}+[\mathbf{C}] \dot{\mathbf{u}}+[\mathbf{M}] \ddot{\mathbf{u}}=\mathbf{F}(t)
$$

where $\mathbf{u}$ represents the vector of particle displacement, $[\mathbf{M}]$ the diagonal mass matrix, $[\mathbf{C}]$ the damping matrix, $\mathbf{F}(t)$ the vector of external forces on particles. The motion equation of the particle system is solved through a explicit center finite differences scheme. The calculation cycle is illustrated in Fig 1(b). Given the particle displacements (either prescribed initially or obtained from the previous time step), new contacts and broken bonds are detected. The list of neighboring particles for each particle is updated. Then, contact and spring forces between particles are calculated according to the prescribed force-displacement relations.

The interaction between particles is represented by one normal spring and one shear spring. The shear spring is a multi body spring which is different from the conventional lattice spring methods. The multi-body shear spring is introduced to make the model can handle problems which Poisson's ratio is beyond 0.25 . The behavior of normal spring is in a conventional way. For example, there existing one bond be- 


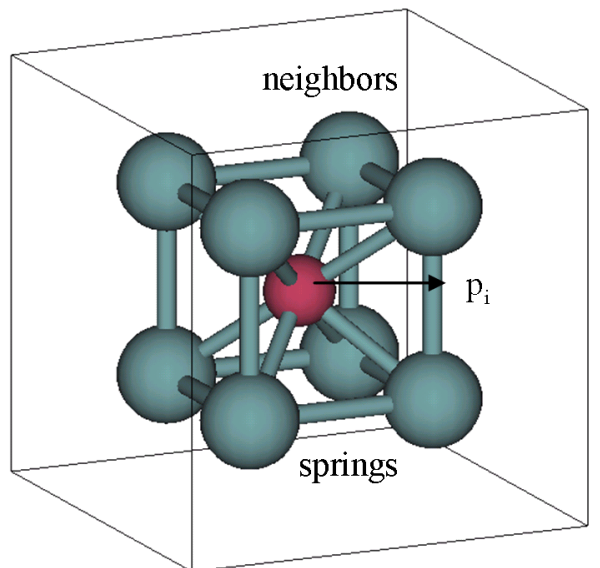

a)

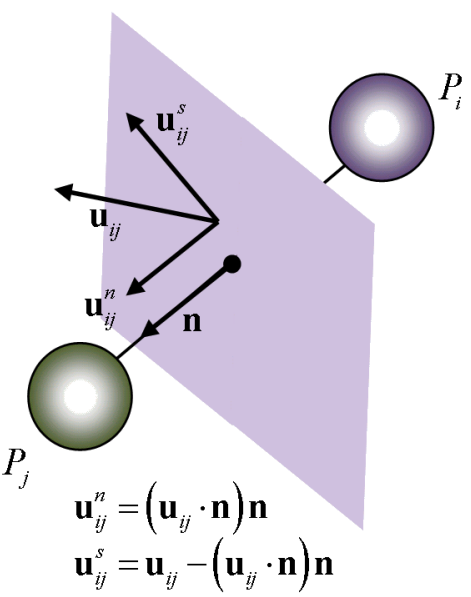

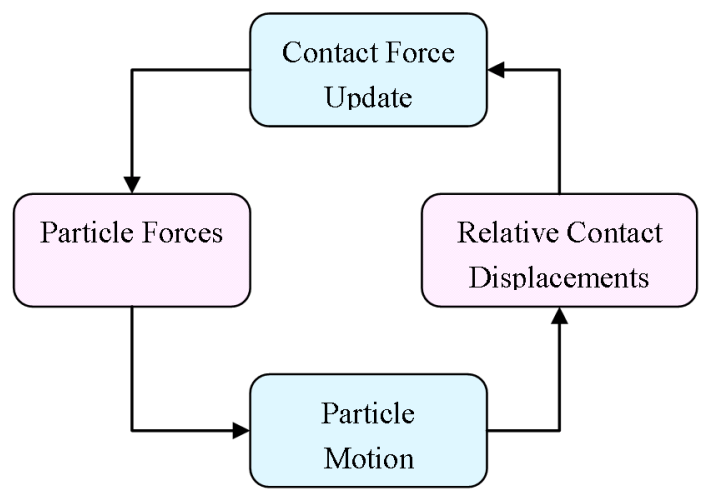

b)
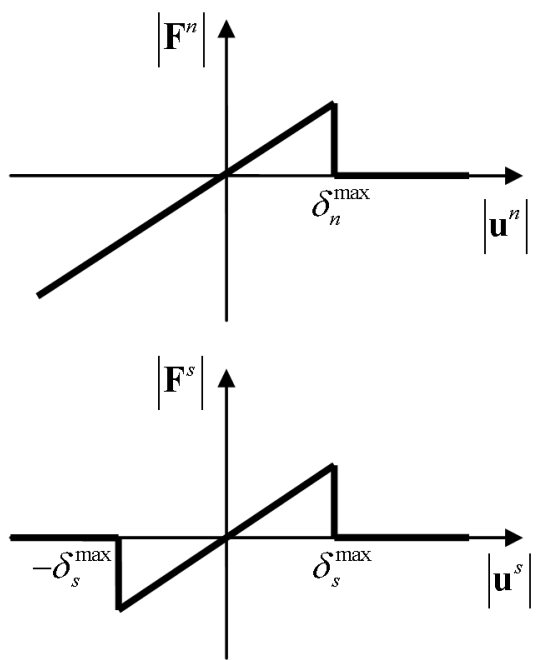

d)

Fig. 1. The physical model, calculation cycle, particle spring deformation and its constitutive law in DLSM.

tween particle $i$ and particle $j$. The unit normal $n\left(n_{x}, n_{y}, n_{z}\right)$ points form particle $i$ to particle $j$. The relative displacement is calculated as

$$
\mathrm{u}_{i j}=\mathrm{u}_{j}-\mathrm{u}_{i}
$$

Then, the vector of normal displacement and interaction force between two particles (see Fig $1(\mathrm{c}, \mathrm{d}))$ can be given as

$$
\mathrm{u}_{i j}^{n}=\left(\mathrm{u}_{i j} \bullet \mathrm{n}\right) \mathrm{n} \text { and } \mathrm{F}_{i j}^{n}=k_{n} \mathrm{u}_{i j}^{n}
$$

where $k_{n}$ is the stiffness of the normal spring and $\mathrm{n}$ is the normal of the bonds. The multibody shear spring between two particles is introduced through a spring with a multi-body shear displacement vector which can be obtained from:

$$
\mathrm{u}_{i j}^{s}=[\boldsymbol{\mu}]_{b o n d} \mathrm{n}^{\mathrm{T}}-\left(\left([\boldsymbol{\mu}]_{b o n d} \mathrm{n}^{\mathrm{T}}\right) \bullet \mathrm{n}\right) \mathrm{n}
$$

where $[\boldsymbol{\mu}]_{\text {bond }}$ is the strain state of the bond which is evaluated by DLSM method. Then, the shear interaction between two particles is given as

$$
\mathrm{F}_{i j}^{s}=k_{s} \mathrm{u}_{i j}^{s}
$$

where $k_{s}$ is the stiffness of the shear spring. Equations (4) to Equation (6) provide the formulas for force update in DLSM. For the displacement update, the particle velocity is advanced individually as

$$
\dot{\mathbf{u}}_{i}^{(t+\Delta t / 2)}=\dot{\mathbf{u}}_{i}^{(t-\Delta t / 2)}+\frac{\sum \mathbf{F}_{j}^{(t)}}{m_{p}} \Delta t
$$

where $\dot{\mathbf{u}}_{i}^{(t+\Delta t / 2)}$ is the particle velocity at $t+\Delta t / 2, \quad \dot{\mathbf{u}}_{i}^{(t-\Delta t / 2)}$ isthe particle velocity at $t-\Delta t / 2, m_{p}$ is the particle mass, $\sum \mathbf{F}_{j}^{(t)}$ is the sum of forces acting on the particle $i$ including applied external forces and $\Delta t$ is the time step. The solution scheme used in distinct lattice spring method (DLSM) is conditionally sta- 
ble. The time step could be calculated according to the time is less than the time for elastic wave propagation through the smallest element of the model. Finally, the new displacement of particle is obtained as

$$
\mathrm{u}_{i}^{(t+\Delta t)}=\mathrm{u}_{i}^{(t)}+\dot{\mathrm{u}}_{i}^{(t+\Delta t / 2)} \Delta t
$$

where $\mathrm{u}_{i}^{(t+D t)}$ is the displacement at $t+\Delta t, \mathrm{u}_{i}^{(t)}$ the displacement at $t$. These two equations are the main procedure involved in the implementation of DLSM. Details of the implementation of DLSM and verifications of DLSM on modeling elastic problems can be found in $[4,6]$. The DLSM still did not used to simulate anisotropic material, and the methodology used in this paper is introduced in next section.

\section{DLSM modeling of nuclear waste disposal galleries in anisotropic medium}

\subsection{Represent anisotropic material in $D L S M$}

The anisotropic material is represented through a two phase DLSM model. It is made up from the base material and the weakness material as shown in Figure 2(a). For anisotropic materials, there are two macro elastic modulus, i.e., the elastic modulus parallel with the bedding plane $E_{p}^{\text {macro }}$ and that in normal direction of the bedding plane $E_{n}^{\text {macro }}$. These two modulus are obtained as [10]:

$$
\begin{aligned}
& E_{p}^{\text {macro }}=E_{\text {base }}(1+\beta(\alpha-1)) \\
& E_{n}^{\text {macro }}=E_{\text {base }} \frac{\alpha}{\alpha(1-\beta)+\beta}
\end{aligned}
$$

where $E_{\text {base }}$ is the elastic modulus of the base material, $\alpha=E_{\text {weak }} / E_{\text {base }}$ is the ratio of the elastic modulus of weak material to that of the base material and $\beta$ is the volume contain ratio of the weak material. Then, the anisotropic ratio $\kappa$ is obtained as

$\kappa=\frac{E_{n}^{\text {macro }}}{E_{p}^{\text {macro }}}=\frac{\alpha}{(\alpha(1-\beta)+\beta)(1+\beta(\alpha-\mathbf{1}))}$

The 3D surface of Equation (12) is given in Figure $2(\mathrm{~b})$. Then, after the volume ratio $\beta$ and anisotropic ratio $\kappa$ are given, the $\alpha$ can be determined through the curve of $\kappa$ versus $\alpha$. The elastic modules of the base and weak material can be obtained as

$$
E_{\text {base }}=\frac{E_{p}^{\text {macro }}}{(\mathbf{1}+\beta(\alpha-\mathbf{1}))} \text { and } E_{\text {weak }}=\alpha E_{\text {base }}
$$

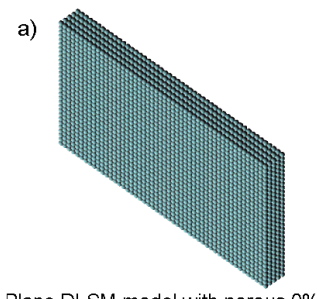

b)
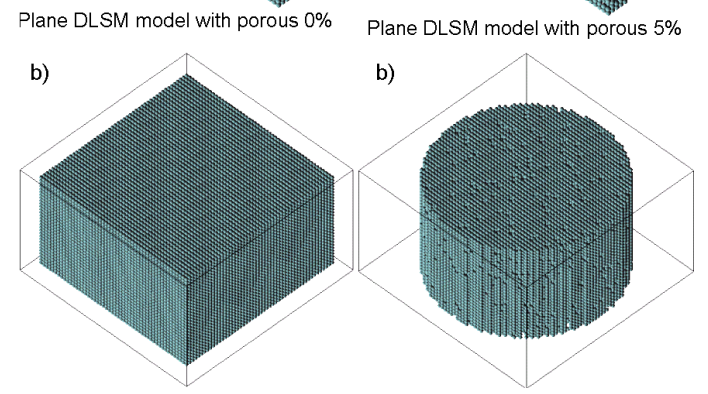

DLSM 3D cubic model with porous $0 \%$

DLSM cylinder model with porous $5 \%$

Fig. 2. Representation of anisotropic material in DLSM and relationship between the anisotropic ratio $\kappa$ and ratio of elastic modulus a and ratio of volume $b$ between the base material and the weak material. (a) Two-phase model; (b) The anisotropic ratio $\kappa$

The Poisson's ratio of both the base material and the weak material is taken the value of the macro Poisson's ratio in direction parallel with the bedding plane. Relationship between macro and micro failure parameter is given as [6]

$$
u^{*}=\frac{\sigma_{t} d^{*}}{E}
$$

where $u^{*}$ is the ultimate deformation for the bond spring in DLSM and $d^{*}$ is the mean particle size. For the anisotropic DLSM model, there will have two parameters related to base material and weak material, respectively. They are suggested to taken as:

$$
u_{\text {base }}^{*}=\frac{\sigma_{t}^{p} d^{*}}{E_{\text {base }}}, u_{\text {weak }}^{*}=\gamma \frac{\sigma_{t}^{n} d^{*}}{E_{\text {weak }}}
$$

where $u_{\text {base }}^{*}$ and $u_{\text {weak }}^{*}$ are the ultimate bond deformation of base material and weak material, respectively, $\gamma$ is a safety factor for the weak material. The reason is that bedding plane usually can bear larger deformation than that of the base material (in this paper $\gamma=100$ ).

\subsection{The computational model}

The computational model used to simulate a kind of indurated clay (Opalinus Clay) as a host medium in Switzerland nuclear waste disposal galleries is shown in Figure 3(a). The diameters of inner and outer hole are $14 \mathrm{~mm}$ and $86 \mathrm{~mm}$, respectively. The two-phase model as described in previous section is used to simulate the anisotropic materials. The mechanical properties are taken from Mont Terri rock laboratory in Switzerland [11], which are given 

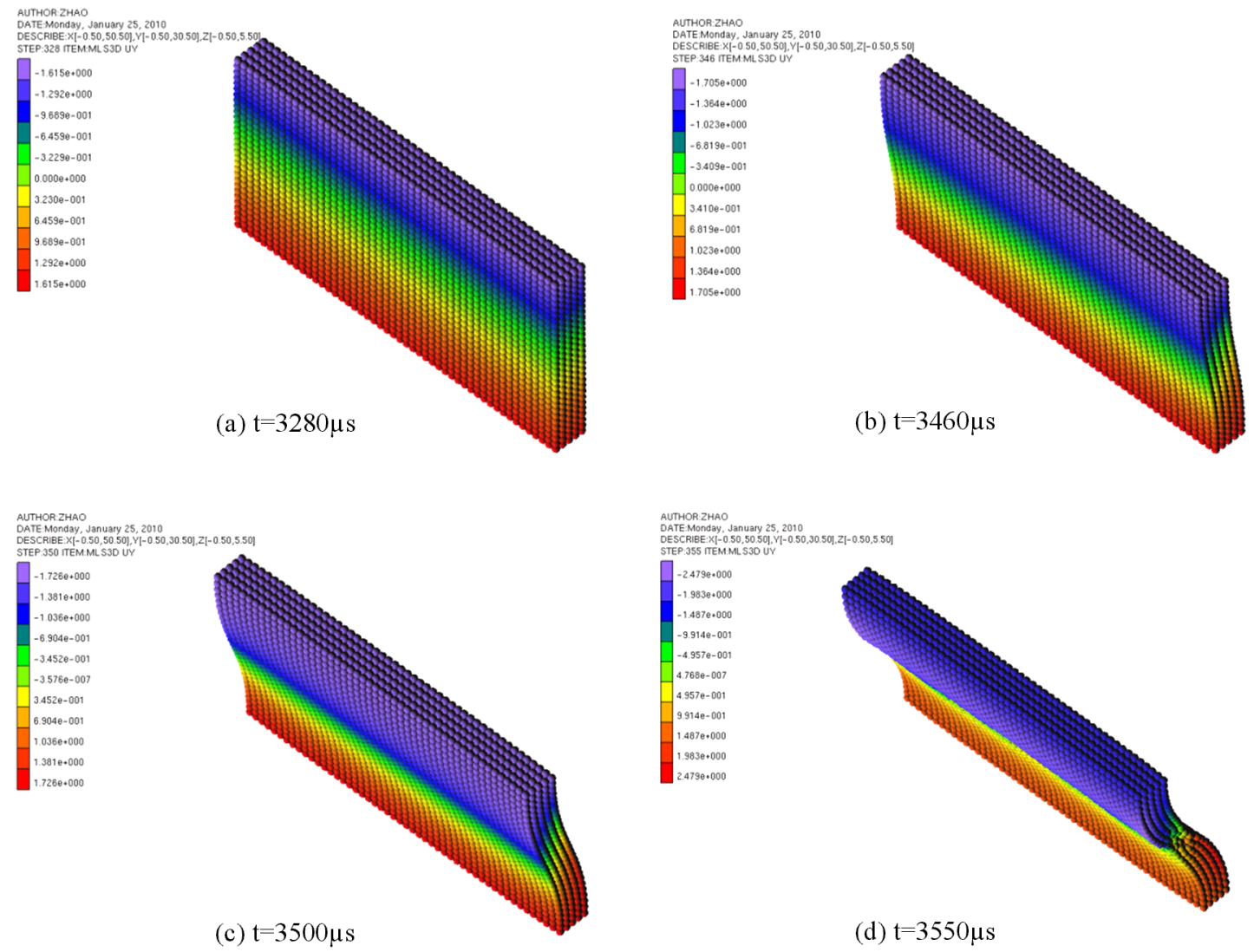

(d) $\mathrm{t}=3550 \mu \mathrm{s}$

Figure 3. The compuational model of nuclear waste disposal galleries in the indurated clay and the boundary condtion to represent the unloading process.

Table 1. Loading cases for the dynamic compressive tests.

\begin{tabular}{|c|c|c|c|c|c|c|c|c|}
\hline \multirow{2}{*}{ Loading cases } & \multicolumn{2}{|c|}{ Low } & \multicolumn{3}{c|}{ Medium } & \multicolumn{3}{c|}{ High } \\
\cline { 2 - 8 } & 1 & 2 & 3 & 4 & 5 & 6 & 7 & 8 \\
\hline$v_{0}(\mathrm{~m} / \mathrm{s})$ & $1.5 \cdot 10^{-3}$ & 0.015 & 0.15 & 0.45 & 0.75 & 1.8 & 2.4 & 3.0 \\
\hline$\dot{\varepsilon}\left(\mathrm{s}^{-1}\right)$ & 0.1 & 1 & 10 & 30 & 50 & 120 & 160 & 200 \\
\hline
\end{tabular}

as follows: the Young's modulus normal to bedding is $2800 \mathrm{MPa}$, the Young's modulus parallel to bedding is $7200 \mathrm{MPa}$, the Poisson's ratio normal to bedding is 0.33 , the Poisson's ratio parallel to bedding is 0.24 , the tensile strength normal to bedding is $1 \mathrm{MPa}$ and that parallel to bedding is $2 \mathrm{MPa}$. Here, the volume ratio $\beta$ of the built DLSM model is given as 0.5. From Equations (10) to (15), the mechanical parameters needed for the two phase DLSM model are calculated and listed in Table I.

The mechanical unloading process is simulated by reducing the central hole walls stress from 4.5 to $0.2 \mathrm{MPa}$ step by step, the stress around outer boundary keeps constant at 4.5MPa (see Fig 3(b)). This is similar to that will be experienced by host rocks around gal- lery constructions. The initial strain and stress state is obtained through a static analysis. Then, the explicit dynamic calculation is performed.

\subsection{Development of excavation damage} zone under mechanical unloading

The DLSM modeling results of mapping displacement contour and excavation damage zone (EDZ) around the nuclear waste disposal galleries in anisotropic medium are shown in Figure 4. It can be seen that the nuclear waste disposal galleries will generally be fractured under the decreasing of the pressure on the inner hole. In the direction parallel to the bedding plane, the main crack develop along the matrix layer by layer due to the decrease 


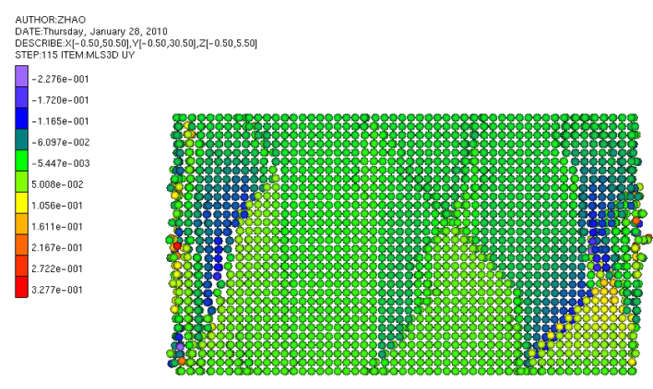

(a) DLSM plane model with porous of $0 \%$

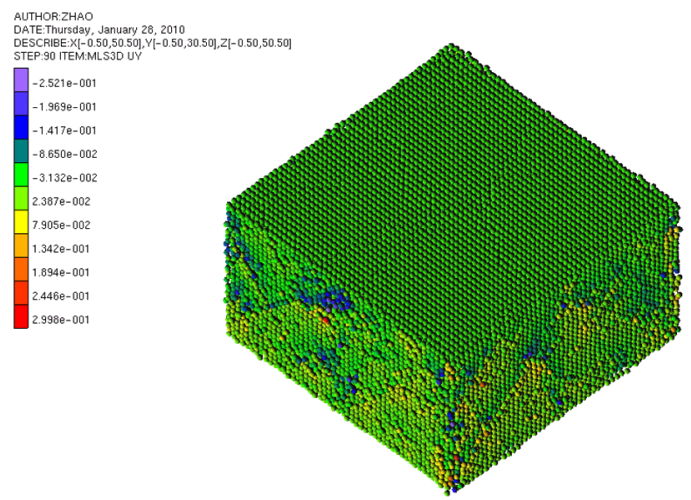

(c) DLSM 3D cubic model with porous of $0 \%$

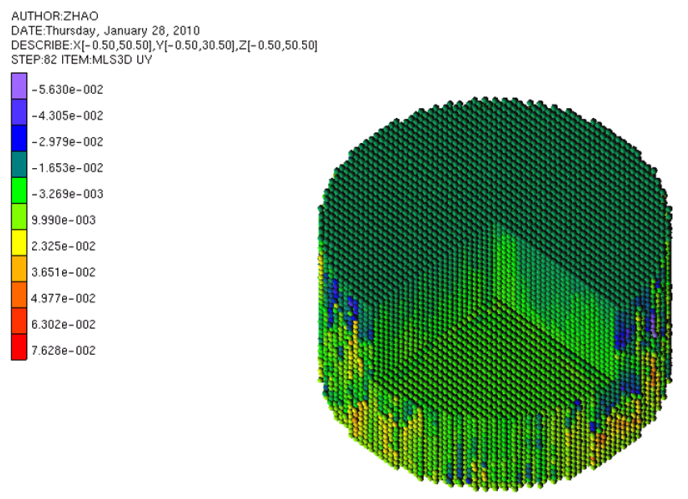

(e) DLSM cylinder model with porous of $0 \%$

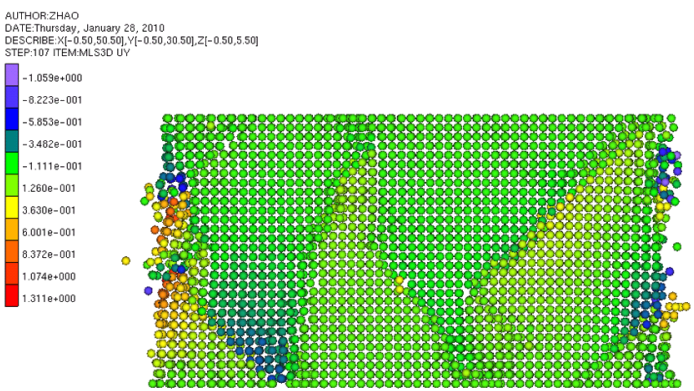

(b) DLSM plane model with porous of $5 \%$

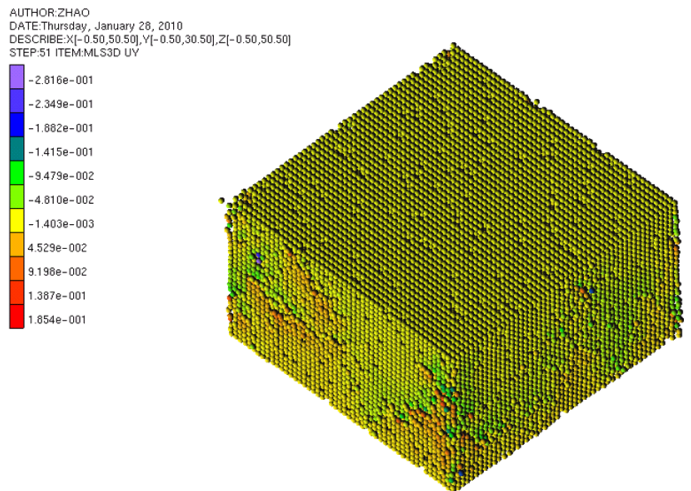

(d) DLSM 3D cubic model with porous of 5\%

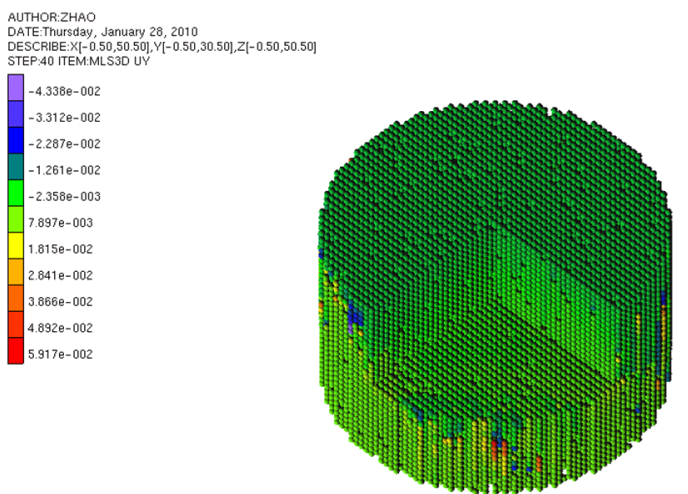

(f) DLSM cylinder model with porous of $5 \%$

Fig. 4. Development of excavation damage zone around the nuclear waste disposal galleries in the indurated clay when decreasing the central pressure.

of central hole pressure. For the influence of weakness layer induced mechanical anisotropy, the movement of particles in bedding planes direction is smaller than in the vertical ones. An oval-shape damage zone induced, which means a significant mechanical anisotropy of indurated clay related to its bedding planes.

\section{Conlusions}

The DLSM is used to study the mechanical unloading process of the nuclear waste disposal galleries in the anisotropic medium. The process is similar to those that will be experienced by host rocks around the gallery constructions. As a discrete based model, DLSM is more suitable to simulate fracturing process than the conventional continuum based models. The mechanical unloading process is successfully simulated through using a two phase DLSM model. The anisotropic deformation and excavation damage zone can be found. It is pointed out that the bedding planes play an important role in mechanical anisotropy of indurared clay, it should be considered carefully 
Table 2. The UCS for different models

\begin{tabular}{|c|c|c|c|c|c|c|}
\hline Loading case & DLSM 1 & DLSM 2 & DLSM 3 & DLSM 4 & DLSM 5 & DLSM 6 \\
\hline 1 & 75.5060 & 23.8048 & 54.9592 & 21.2952 & 57.3571 & 20.3024 \\
\hline 2 & 76.1272 & 26.1684 & 55.2460 & 22.8440 & 57.3981 & 21.4325 \\
\hline 3 & 75.8716 & 32.5044 & 56.0272 & 26.3206 & 57.7343 & 26.0134 \\
\hline 4 & 76.3140 & 36.62 & 58.6256 & 28.7386 & 58.2421 & 28.6826 \\
\hline 5 & 77.3956 & 38.3684 & 60.2248 & 30.3303 & 58.7559 & 30.1092 \\
\hline 6 & 81.9028 & 41.0004 & 64.2036 & 32.380 & 59.418 & 32.8552 \\
\hline 7 & 83.5072 & 42.1032 & 66.4456 & 33.3066 & 59.9711 & 33.6561 \\
\hline 8 & 83.7188 & 43.3096 & 66.7392 & 33.6927 & 59.8973 & 33.6100 \\
\hline
\end{tabular}

Table 3. DIFs of different models.

\begin{tabular}{|c|c|c|c|c|c|c|}
\hline Loading case & DLSM 1 & DLSM 2 & DLSM 3 & DLSM 4 & DLSM 5 & DLSM 6 \\
\hline 1 & 1.0000 & 1.0000 & 1.0000 & 1.0000 & 1.0000 & 1.0000 \\
\hline 2 & 1.0082 & 1.0993 & 1.0052 & 1.0727 & 1.0000 & 1.0557 \\
\hline 3 & 1.0048 & 1.3655 & 1.0194 & 1.236 & 1.0059 & 1.2813 \\
\hline 4 & 1.0107 & 1.5383 & 1.0667 & 1.3495 & 1.0147 & 1.4128 \\
\hline 5 & 1.025 & 1.6118 & 1.0958 & 1.4243 & 1.0237 & 1.4830 \\
\hline 6 & 1.0847 & 1.7224 & 1.1682 & 1.5205 & 1.0352 & 1.6183 \\
\hline 7 & 1.106 & 1.7687 & 1.2090 & 1.564 & 1.0448 & 1.6577 \\
\hline 8 & 1.1088 & 1.8194 & 1.2143 & 1.5822 & 1.0435 & 1.6555 \\
\hline
\end{tabular}

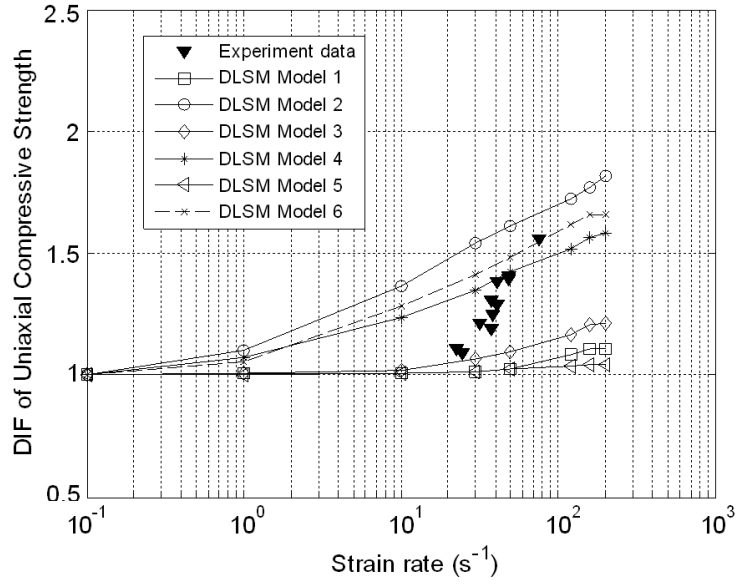

Fig. 5. Development of excavation damage zone around the nuclear waste disposal galleries in the indurated clay when decreasing the central pressure.

in the design of nuclear waste disposal galleries in anisotropic medium.

\section{Acknowledgment}

The financial supports from the China Scholarship Council, TIMODAZ project is co-funded by the European Commission and performed as part of the sixth EURATOM Framework Programme for nuclear research and training activities (2002-2006), and Swiss National Science Foundation (200021-116536) to the authors are gratefully acknowledged.

\section{References}

1. B. Amadei, Intern. J. Rock Mech.Min., 33(3), 293, 1996..

2. S. You, V.Labiouse, L. Vigne, L.Gastaldo, M.Bernasconi, Proc, Euro10, 2010, P 755.

3. G.F. Zhao, J.Zhao, Proc. ICADD9 Analysis of Discontinuous Deformation: New Developments and Applications, 2009, P 633.

4. G.F.Zhao, J.Fang, J.A. Zhao, Int. J. Numer. Anal. Meth., 2010, doi 10.1002/nag.930 .

5. G.F.Zhao, Proc, 1st EPFL Doctoral Conference in Mechanics, Advances in modern aspects of mechanics. 2010, P 37.

6. G.F.Zhao, Development of micro-macro continuum-discontinuum coupled numerical method, PhD thesis. EPFL, 2010.

7. T. Kazerani, G. F.Zhao, J. Zhao, Rock Mech. Rock Eng., 2010 DOI: 10.1007/s00603-010-00990.

8. G.F.Zhao, L. Sun, J.B.Zhu, J.N. Fang, Proc, Euro10, 2010, P. 177.

9. Z.N.Zhang, X.R.Ge, Theor. Appl. Fract. Mech., 43, 342, 2005.

10. G.F. Zhao, Master thesis, CUMT, 2007.

11. P. Bossart, M.Thury, Mont Terri Rock Laboratory. Project, Programme 1996 to 2007 and Results. - Rep. Swiss Geol. Surv. 3., (2008) 